\title{
The diagnostic utility of inmunohistochemical and electronic microscopy in distinguishing between pleural mesothelioma and adenocarcinoma
}

\author{
Carlos González Carrillo C1, Hugo Dominguez Malagón*1 and Oscar Arrieta²
}

\author{
Address: ${ }^{1}$ Department of pathology, National Cancer Institute, Mexico City, Mexico and ${ }^{2}$ Medical Oncology Department, Instituto Nacional de \\ Cancerologia. Mexico City, Mexico \\ Email: Hugo Dominguez Malagón* - hdominguezm@terra.com.mx \\ * Corresponding author
}

from 24th Annual Meeting of the National Cancer Institute of Mexico

Mexico City, Mexico. 14-17 February 2007

Published: 5 February 2007

BMC Cancer 2007, 7(Suppl I):A32 doi:10.1 186/147I-2407-7-SI-A32

This article is available from: http://www.biomedcentral.com/I47I-2407/7/SI/A32

(c) 2007 Carrillo C et al; licensee BioMed Central Ltd.

\section{Background}

The mesothelioma is a mesodermic tumor localized in the pleura in $70-90 \%$ of the cases, with an incidence of $2 \times$ 100,000 habitants per year in women and 10-30 $\times$ 100,000 habitants per year in men. The diagnosis is realized by cytology, guided biopsy by computed tomography and electronic microscopy which is the gold standard where we can observe several nodes in the visceral and parietal pleura where are produced effusion pleural. The objective of this trial was to realize the inmunohistochemical and structural study of the effusion pleural in patients with lung tumors in which we suspect the presence of mesothelioma versus adenocarcinoma to show is an adequate diagnosis method.

\section{Materials and methods}

The material utilized in this trial was obtained in the cytopathology and pathology department of the respiratory disease institute. We studied thirty effusion pleural fluids of ten patients with the diagnosis of mesothelioma and ten patients with the diagnosis of adenocarcinoma during the period between August and November. We realized the determination of calretinina and keratin (CK) and the ultrastructural study with the electronic microscopy.

\section{Results}

The patients with mesothelioma diagnosis were calretinina positive which confirms the histological diagnosis. We observed in the electronic microscopy profussion of microvilli in the surface cells. The adenocarcinoma fluids were CK positive and negative for the rest of the test.

\section{Conclusion}

We demonstrate that we can distinguish between pleural mesothelioma and adenonocarcinoma by inmunohistochemical test and electronic microscopy, these diagnosis methods may be an option for patients in whom are contraindicated the biopsy realization, besides they may be cheaper and quicker than the biopsy. 